\title{
Exposure to violence and its relationship to psychopathology in adolescents
}

\author{
C L Ward, A J Flisher, C Zissis, M Muller, C Lombard
}

\begin{abstract}
Objectives-This study aimed to establish prevalence of adolescents' exposure to violence and related symptoms in the South African context and to explore relationships between exposure and symptoms.

Setting-Four high schools in Cape Town, South Africa.

Methods-Self report questionnaires were administered to 104 students. Types of violence explored included: witnessing or being a victim of violence perpetrated by someone known to the child or in the home and witnessing or being a victim of violence perpetrated by a stranger. The Harvard Trauma Scale, Beck Depression Inventory, and Zung Self-Rating Anxiety Scale were used to assess potentially related symptoms.

Results-The majority of children had been exposed to at least one type of violence, and exposure to the one type of violence was related to the other type. Symptoms of post-traumatic stress disorder and depression appear to be related to most types of exposure to violence, but anxiety symptoms only to exposure to violence perpetrated by someone known to the child or in the home.

Conclusions-Rates of exposure to violence, and related symptoms, were unacceptably high. Symptoms were associated with exposure to violence.

(Injury Prevention 2001;7:297-301)
\end{abstract}

Keywords: adolescents; violence; mental health; psychopathology

Exposure to violence is a risk factor for physical injury and has implications for mental health. South Africa has high levels of violence. Approximately 60 deaths per 100000 are due to homicide (10 times the rate in the United States). ${ }^{1}$ Both international and local studies indicate that those who witness or are victims of traumatic events may experience a range of negative outcomes, including symptoms of depression, anxiety, and post-traumatic stress disorder (PTSD). ${ }^{2-4}$ Aside from psychiatric symptoms, adolescents who have been victims or witnesses of violence are also likely to exhibit poor school performance and behavioural disorders which jeopardise their ability to function well later in life. ${ }^{56}$

Although the effects of such exposure have been documented in the literature, our understanding of these is limited in crucial respects. Firstly, South African studies have been based on data that predate the end of apartheid, ${ }^{7}$ and thus reflect a different social milieu, or are more directly limited to the study of PTSD as a consequence of either a specific type of violence $^{8}$ or of undifferentiated types of community violence. ${ }^{3}$ Other South African studies have been limited either to samples exposed to a specific event, ${ }^{4}$ to psychiatric samples, ${ }^{9}$ or to rural samples. ${ }^{10}$

Secondly, studies also suggest that categories of exposure to violence may be related. For instance, there is evidence that witnessing spousal violence and being a victim of child abuse are often both experienced by the same children, and that both may lead to the development of mental health symptoms in children. ${ }^{11}$ Similarly, in contexts of high levels of community violence, high levels of family violence may also occur. ${ }^{12}$ Yet there is very little literature that examines these relationships despite their implications for prevention efforts. For instance, from this perspective, programmes that seek to prevent spousal abuse also prevent poor mental health outcomes for children.

Finally, there is also evidence that different types of exposure (as witness or victim) to different types of violence (for example, violence in the home versus violence experienced outside the family circle) may have different sequelae. ${ }^{13}$ Studies that focus exclusively on PTSD as a consequence of exposure to violence may miss the range of psychiatric symptoms that possibly result from exposure to different types of violence. ${ }^{56}$ Similarly, while anxiety, depression, and PTSD are frequently comorbid with each other, ${ }^{2}$ differentiating which types of exposure are mostly likely to cause which symptoms may have implications for treatment. Again, data from epidemiological studies are essential.

This study documents selected aspects of exposure to violence and psychopathology among adolescents in Cape Town. It addresses the limitations that were present in previous studies by: (1) using a recent school based sample and including exposure to different types of violence; (2) examining the relationships between exposure to different types of violence; and (3) investigating relationships between different categories of violence and different symptoms.

\section{Methods}

SAMPLE

This study forms part of a larger study, in which many aspects of adolescent risk behaviour were examined, and was a preliminary to a later study in the publicly funded schools. Part of the intent of this study was to assess the testretest reliability of the instruments, thus
Africa

cward@curie.uct.ac.za 
requiring two administrations of the questionnaires. Although public sector schools were approached for participation in this study, access was denied on the basis of the disruption caused by administering bulky questionnaires twice for this study, and then a third time for the later, larger study.

The sample was thus drawn from four private schools in Cape Town, South Africa. Schools which endorsed a non-mainstream educational philosophy or specific religious orientation were not eligible for selection. The only other school which satisfied the criteria was also approached but declined to participate. One school was for boys only, one for girls only, and two were coeducational. These schools have relatively more boys than girls as students, and so approximately $70 \%$ of the student body is male. All four schools used English as the medium of instruction, and are thus-barring gender distribution - as similar as possible to the schools in the public sector. Permission for their children's participation was obtained from all parents via passive consent, and all students present at school on the day were included in the sample.

All students in grade 11 (age approximately 17 years) received part 1 of the questionnaire but only every third student received part 3, the section related to violence. Parts $2-4$ of the questionnaire were randomly distributed among the students. Part 1 contained the demographic questions, as well as other information that was not relevant to this particular study. Parts 2 and 4 addressed other aspects of adolescent risk behaviour that are not included in this report. In total, 358 students received a questionnaire each. Of these, 49 questionnaires were rejected, either because the participant number was missing or obviously incorrect or duplicated; or because they were blank. Of the violence questionnaires, 104 were included in this study.

\section{MEASURES}

Questionnaires addressed demographic characteristics, feelings of safety, and the Zung Self-Rating Anxiety Scale, the Beck Depression Inventory, and the Harvard Trauma Scale. Level of language was appropriate for grades $8-11$. The questionnaire took approximately 40 minutes to complete and similar questionnaires have been used in other school based epidemiological studies. ${ }^{14}$

Part 3 of the questionnaire started with four questions about feelings of safety at school, home, away from home, and with one's family. These were answered on a four point scale, with answers ranging from "always" (coded 1) to "not at all" (coded 4). Summary scores for this section, dubbed the "safety index", range from 4 to 16 .

The Harvard Trauma Scale was used to address both exposure to violence and symptoms of PTSD..$^{15}$ This scale was first developed to address the experience of Indochinese refugees in the United States. Here it is adapted slightly to address violence that is most likely to occur in South Africa. For instance, instead of asking about torture related events, such as lack of food and water, questions were asked about beatings, shootings, and stabbings.

The Beck Depression Inventory and Zung Self-Rating Anxiety Scale were used to assess symptomatology broader than that addressed by the Harvard Trauma Scale. Both have shown strong psychometric properties and been useful as screening instruments in adolescent populations. ${ }^{1617}$

\section{PROCEDURES}

Questionnaires were administered in the classroom, and care was taken to ensure privacy and anonymity. Students were given the name of a mental health helpline in case any of them was distressed by the questions that were asked. In addition, the research assistants invited anyone who had questions to speak to them privately after the questionnaire had been completed. The assistants were also trained to seek out actively any student who appeared distressed.

\section{ANALYSIS}

Questions addressing exposure to violence were grouped into four categories of exposure, two addressing violence perpetrated by someone known to the child or in the home ("known" violence), and another two to violence perpetrated by a stranger ("stranger" violence). One category addressed being a victim of "known" violence (16 questions) such as "Someone I know threatened to stab me". Another comprised 18 questions related to witnessing "known" violence, including items such as "I have seen a member of my family get stabbed in my home" and "I have seen a stranger get stabbed in my home". Nine questions addressed the child's experience of being a victim of "stranger" violence, and included such questions as "I have been beaten up by a stranger". The final category comprised six questions addressing the child's experience of witnessing "stranger" violence. Questions included "I have heard gunshots" and "I have seen a stranger get stabbed".

Frequencies for each set of symptoms, and for various types of exposure, were then calculated. Spearman correlations between these variables, and between these variables and each scale score, were calculated.

Questionnaires with extensive missing values were not included in the analysis. In the questionnaires where missing values still occurred, the scores were based on the non-missing responses. This approach gives a conservative estimate of exposure and symptoms for these students.

Table 1 Percentages of children experiencing different types of violence $(n=104)$

\begin{tabular}{lll}
\hline Type of violence & $\begin{array}{l}\text { No of } \\
\text { children } \\
\text { exposed }\end{array}$ & $\begin{array}{l}\% \text { Of } \\
\text { sample } \\
\text { exposed }\end{array}$ \\
\hline Witnessing stranger violence & 85 & 81.7 \\
Victim of stranger violence & 32 & 30.8 \\
Witnessing "known" violence & 64 & 61.5 \\
Victim of "known" violence & 50 & 48.1 \\
Victim or witness of "known" violence & 74 & 71.1 \\
Victim or witness of stranger violence & 86 & 82.7 \\
\hline
\end{tabular}


Table 2 Correlations between exposure to types of violence

\begin{tabular}{|c|c|c|c|c|c|}
\hline & $\begin{array}{l}\text { Victim of stranger } \\
\text { violence }\end{array}$ & \multicolumn{2}{|c|}{$\begin{array}{l}\text { Witness of "known" } \\
\text { violence }\end{array}$} & \multicolumn{2}{|c|}{$\begin{array}{l}\text { Victim of "known" } \\
\text { violence }\end{array}$} \\
\hline $\begin{array}{l}\text { Witness of stranger violence } \\
\text { Victim of stranger violence } \\
\text { Witness of "known" violence }\end{array}$ & $0.46^{\star}$ & \multicolumn{2}{|l|}{$\begin{array}{l}0.34^{\star} \\
0.46^{\star}\end{array}$} & \multicolumn{2}{|c|}{$\begin{array}{l}0.28^{\star} \\
0.46^{\star} \\
0.37^{\star}\end{array}$} \\
\hline \multicolumn{6}{|l|}{${ }^{\star} \mathrm{p}<0.01$} \\
\hline & \multicolumn{5}{|c|}{$\begin{array}{l}\text { Table } 3 \text { Percentages of children endorsing symptoms } \\
(n=104)\end{array}$} \\
\hline & Symptom scale sco & & \multicolumn{2}{|c|}{$\begin{array}{l}\text { No of children } \\
\text { endorsing } \\
\text { symptoms }\end{array}$} & $\begin{array}{l}\% \text { Of children } \\
\text { endorsing } \\
\text { symptoms }\end{array}$ \\
\hline & \multicolumn{2}{|c|}{$\begin{array}{l}\text { Meeting full criteria for PTSD } \\
\text { No of PTSD symptoms }\end{array}$} & \multicolumn{2}{|l|}{6} & 5.8 \\
\hline & \multicolumn{2}{|c|}{$0-7$} & 59 & & 56.7 \\
\hline & \multicolumn{2}{|l|}{$8-15$} & 25 & & 24.1 \\
\hline & \multicolumn{2}{|l|}{$16-23$} & 18 & & 17.3 \\
\hline & \multicolumn{2}{|l|}{$24-30$} & 2 & & 1.9 \\
\hline & \multirow{2}{*}{\multicolumn{2}{|c|}{$\underset{<21^{\star}}{\text { Depression score }}$}} & & & \\
\hline & $<21^{\star}$ & & 9 & & 8.6 \\
\hline & \multicolumn{2}{|l|}{$21-36$} & 84 & & 80.8 \\
\hline & \multicolumn{2}{|l|}{$37-52$} & 11 & & 10.6 \\
\hline & \multicolumn{2}{|l|}{$53-84$} & 0 & & 0 \\
\hline & \multicolumn{5}{|l|}{ Anxiety score } \\
\hline & \multirow{2}{*}{\multicolumn{2}{|c|}{$\begin{array}{l}<19^{\star} \\
19-32\end{array}$}} & 2 & & 1.9 \\
\hline & & & 62 & & 59.6 \\
\hline & \multicolumn{2}{|l|}{$33-47$} & 39 & & 37.5 \\
\hline & \multicolumn{2}{|l|}{$48-62$} & 1 & & 1.0 \\
\hline & \multicolumn{2}{|l|}{$63-76$} & 0 & & 0 \\
\hline
\end{tabular}

^Scores lower than the possible minimum for the scale were found because missing values were based on the non-missing responses, giving a conservative estimate of symptoms.

\section{Results}

SAMPLE

The sample consisted of 104 students in grade 11. Of these, $71(68 \%)$ were male, and 32 (31\%) were female (one respondent did not report his/her gender).

EXPOSURE TO VIOLENCE

It is clear from table 1 that many children have been exposed to at least one of the types of violence that we explored in this study. The safety index, however, indicated that most children felt safe in most places. The mean score for the safety index was 13.18 (confidence interval 12.77 to 13.59 ) out of a possible maximum score of 16 . In addition, table 2 shows that all the correlations between the various types of exposure to violence were significant.

SYMPTOMS

Table 3 shows that $5.8 \%$ of this sample were likely to meet criteria for PTSD. Even more children (almost 20\%) experienced more than half of the number of symptoms of PTSD explored in this questionnaire. By contrast, fewer children experienced high numbers of depressive symptoms, although many more experienced anxiety.

Table 4 Correlations between exposure to violence, and symptoms and subjective sense of safety

\begin{tabular}{lllll}
\hline & $\begin{array}{l}\text { PTSD } \\
\text { symptoms }\end{array}$ & $\begin{array}{l}\text { Depression } \\
\text { symptoms }\end{array}$ & $\begin{array}{l}\text { Anxiety } \\
\text { symptoms }\end{array}$ & $\begin{array}{l}\text { Subjective } \\
\text { sense of safety }\end{array}$ \\
\hline Witness of stranger violence & $0.34^{\star}$ & $0.20^{\star}$ & 0.09 & $-0.44^{\star}$ \\
Victim of stranger violence & 0.09 & 0.04 & 0.09 & $-0.31^{\star}$ \\
Witness of "known" violence & $0.30^{\star}$ & $0.24^{\star}$ & $0.26^{\star}$ & $-0.22^{\star}$ \\
Victim of "known" violence & $0.23^{\star}$ & $0.22^{\star}$ & $0.27^{\star}$ & $-0.39^{\star}$ \\
\hline
\end{tabular}

${ }^{\star} \mathrm{p}<0.05$.
Key points

- A total of 104 high school students in Cape Town, South Africa were surveyed about exposure to violence and psychopathology.

- Most children had been exposed to at least one type of violence.

- Types of violence (for example, witnessing violence perpetrated by someone known to the child, and being a victim of stranger violence) tended to be interrelated.

- Symptoms of PTSD and depression appear to be related to most forms of violence.

- Anxiety symptoms appear to be related to violence perpetrated only in the home or by someone known to the child.

RELATIONSHIPS BETWEEN SYMPTOMS AND

EXPOSURE TO VIOLENCE

Table 4 shows that there was a significant negative relationship between children's subjective sense of safety, and their exposure to each category of violence. Significant positive relationships were found between PTSD and depressive symptoms, and exposure to all types of violence, except for victims of stranger violence. Anxiety symptoms, however, showed a significant positive relationship only for witnessing or being a victim of violence perpetrated by someone known to the child.

\section{Discussion}

The purpose of this study was threefold: to investigate adolescents' exposure to violence using a school based sample, to investigate relationships between types of exposure, and to investigate the relationship of this exposure to psychiatric symptoms.

While many of the adolescents in this urban South African sample have avoided exposure to violence, all too many have experienced at least one type of violence, either as witness or victim. Rates shown in table 1 were comparable with international studies of exposure to violence amongst high school youth. ${ }^{518}{ }^{19}$ For instance, Schwab-Stone and her colleagues found that their 1994 sample experienced 0.62 types of violence on average as victims, and witnessed 2.83 types of violence on average (in their study, no differentiation was made between stranger and "known" violence). ${ }^{5}$ However, since missing values in this study were coded as zero, the figures given in this paper are an under-representation of exposure to violence. It is possible that actual rates of exposure are even higher.

Exposure to one type of violence put children at risk for exposure to another type. There are several possible explanations for this. For instance, children who witness spousal abuse are often at risk for child abuse from either the abusing or abused partner. ${ }^{11}$ In addition, children who are exposed to violence in the home may put themselves at risk for experiencing community violence by avoiding the 
home, and those who are exposed to violence may also become aggressive themselves and so invite further exposure. ${ }^{132021}$

Description of symptoms also implies that many children are suffering. Nearly 6\% (95\% confidence interval $1.3 \%$ to $10.3 \%$ ) are likely to have full blown PTSD and $17 \%$ have a high number of symptoms of PTSD. These figures are similar to, although slightly lower than, those obtained in other studies which used samples drawn from the community, rather than clinical samples. ${ }^{101922}$ Rates of depressive and anxiety symptoms found here have a similar relationship to those found in other studies. ${ }^{23}$

Relationships between type of exposure and symptoms are, in most cases, weak but significant. This suggests that, while not all symptoms are directly associated with exposure to violence, symptoms are contributed to by the violence in children's homes and communities. Support for this is found in the consistently significant correlations between children's subjective sense of safety and exposure to violence.

Being a victim of stranger violence was not, however, significantly associated with PTSD, depression, or anxiety. It is possible that in these circumstances, the victim has access to social support, whereas with "known" violence, the danger comes from within the social support group. In addition, "stranger" violence may well consist of discrete episodes, whereas with "known" violence, the danger may be more constantly present. For instance, if one lives with an abusive parent, it is highly likely that the exposure to violence is ongoing. Seeing a shooting or being mugged outside the home is likely to be a less frequent event. Stranger violence may thus be more likely to give children access to protective factors than "known" violence, which appears to undermine resilience more seriously. Future research could clarify these issues.

One of the weaknesses of this study is that exposure to violence was measured as a count of types of violence, rather than as exposure to the number of times violence was experienced. This means that, for instance, a child who was shot once has the same exposure "count" as a child who was shot multiple times. It is possible that this contributes to the weak correlations found in this study.

Other limitations of the study include its small sample size, the fact that the sample was drawn only from private schools, and the fact that only those students actually at school on the day of the questionnaire administration were included in the sample. These limit the generalisability of the findings for two main reasons. Firstly, since these schools are not publicly funded, substantial fees are required of most students. These students thus are likely to be drawn from relatively wealthy families and in most cases to have come from safer communities than students in publicly funded schools. Secondly, the high number of boys in the sample may mean that relatively more weight has been given to boys' experience of violence exposure. This may affect the results, since boys are more likely to experience certain types of violence, such as bullying, ${ }^{24}$ and less likely to be exposed to other types such as rape.

A subsequent study will remedy these drawbacks, using a larger sample drawn from randomly selected publicly funded schools.

\section{Implications for prevention}

It is clear from this small study that levels of violence in children's homes and communities are far too high, putting them at risk for developing potentially serious mental health problems. The public health costs of exposure to violence reside not only in the mental health problems themselves, but in their costs to children in terms of the resultant interference with their academic and social development, which in turn carry a cost to society. ${ }^{25-27}$

Since much of children's exposure to violence appears to be to community violence, community level programmes that seek to prevent violence should form a part of the approach to this problem. School based violence prevention programmes, such as bullying prevention initiatives and those that assist children in identifying and avoiding risky situations, would also be helpful as primary and secondary prevention programmes.

In addition, mental health programmes should address the broad range of symptoms that may result from exposure to violence. All too many studies and initiatives focus solely on PTSD, whereas it is clear that such sequelae are likely to include depressive and anxiety symptoms as well as those related to PTSD.

This study also makes it clear that many children are already suffering the effects of exposure to violence. Tertiary prevention initiatives are needed to address this, given the high rates of symptoms identified here. Prevention programmes could also educate children, parents, and teachers about symptoms and their causes, in order to assist them to identify children who are struggling with these symptoms. Educating other decision makers, such as government officials, both about the effects of exposure to violence and its cost to society will also be helpful in creating an understanding of the magnitude of this problem.

Identifying children at risk and providing treatment for them, and preventing violence, must become matters of high priority for mental health professionals and for government.

Funding was provided by the World Health Organisation Programme on Substance Abuse, the United Nations Development Programme, the South African Medical Research Council, and the University of Cape Town

The authors would like to thank the principals, staff, and stuThe authors would like to thank the principals, staff, and students of the schools that participated in the study; Janet Evans Ensink for assistance with the selection of instruments.

1 Peden M, Butchart A. Trauma and injury. In: Crisp N, Ntuli A, eds. South African health review 1999. Durban: Health Systems Trust, 1999: 331-44.

2 Ursano RJ, Grieger TA, McCarroll JE. Prevention of posttraumatic stress: consultation, training and early treatment. In: Van der Kolk BA, McFarlane AC, Weisaeth, L, mind, body and society. New York: Guildford Press, 1996: mind, body

3 Pillay Y, Magwaza A, Petersen I. Civil conflict in Mpumalanga: some mental health sequelae in a sample of children and their caregivers. S Afr F Child Adolesc Psychiatry $1992 ; 4: 42-5$. 
4 Dawes A, Tredoux C, Feinstein A. Political violence in South Africa: some effects on children of the violent destruction

5 Schwab-Stone M, Chen C, Greenberger E, et al. No safe haven II: the effects of violence exposure on urban youth. $\mathcal{F}$ Am Acad Child Adolesc Psychiatry 1999;38:359-67.

6 Glodich AM. Traumatic exposure to violence: a comprehensive review of the child and adolescent literature. Smith College Studies in Social Work 1998;68:321-45.

7 Flisher AJ, Ziervogel CF, Chalton DO, et al. Risk-taking behaviour of Cape Peninsula high-school students. Par VII. Violent behaviour. S Afr Med F 1993;83:490-4.

8 Ensink K, Robertson BA, Zissis C, et al. Post-traumatic stress disorder in children exposed to violence. $S$ Afr Med $\mathcal{F}$ 1997;87:1526-30.

9 Smith C, Holford L. Post traumatic stress disorder: South Africa's children and adolescents. S Afr F Child Adolesc Psychiatry 1993;5:57-69.

10 Peltzer K. Posttraumatic stress symptoms in a population of rural children in South Africa. Psychol Rep 1999;85:646-50.

1 Shipman KL, Rossman BBR, West JC. Co-occurrence of spousal violence and child abuse: conceptual implications. Child Maltreatment 1999;4:93-102.

12 Sampson RJ. Family management and child development: Insights from social disorganization theory. In: McCord J, ed. Facts, frameworks and forecasts: advances in criminological theory. New Brunswick, NJ: Transaction Publishers, 1992: 63-93.

13 Lynch M, Cicchetti D. An ecological-transactional analysis of children and contexts: the longitudinal interplay among child maltreatment, community violence, and children's symptomatology. Developmental Psychopathology 1998;10: 235-57.

14 Flisher AJ. Guiding aspirations of epidemiological research in adolescent risk behaviour in the Department of Psychiatry, University of Cape Town. $S$ Afr $\mathcal{F}$ Child Adolesc Ment Health 1998;10:140-54.

15 Mollica RF, Caspi-Yavin Y, Bollini P, et al. The Harvard trauma questionnaire: validating a cross-cultural instrutrauma questionnaire: validating a cross-cultural instru-
ment for measuring torture, trauma, and posttraumaticstress disorder in Indochinese refugees. Fournal of Nervous and Mental Disease 1992;180:111-16.
16 Sasson Y, Iancu I, Fux M, et al. A double-blind crossover comparison of clomipramine and desipramine in the treatment of panic disorder. European Neuropsychopharmacology 1999;9:191-6.

17 Sinoff G, Ore L, Zlotogorsky D, et al. Short anxiety screening test-a brief instrument for detecting anxiety in the elderly. International fournal of Geriatric Psychiatry 1999;14: 1062-71.

18 Moses A. Exposure to violence, depression, and hostility in a sample of inner city high school youth. Fournal of Adolescence 1999;22:21-32.

19 Singer MI, Anglin TM, Song L, et al. Adolescents' exposure to violence and associated symptoms of psychological trauma. $7 A M A$ 1995;273:477-82.

20 Aneshensel CS, Sucoff CA. The neighborhood context of adolescent mental health. F Health Soc Behav 1996;37:293310 .

21 Berton MW, Stabb SD. Exposure to violence and posttraumatic stress disorder in urban adolescents. Adolescence 1996;31:489-98.

22 Goodyer IM. The epidemiology of depression in childhood and adolescence. In: Verhulst FC, Koot $\mathrm{H}$, eds. The epidemiology of child and adolescent psychopathology. Oxford: epidemiology of child and adolescent psych

23 Monck E, Graham P, Richman N, et al. Adolescent girls: II. Background factors in anxiety and depressive states. $\mathrm{Br} \mathcal{F}$ Psychiatry 1994;165:770-80.

24 Barbarin OA. Social risks and psychological adjustment: a comparison of African American and South African children. Child Dev 1999;70:1348-59.

25 Gruber J, ed. Risky behavior among youths: an economic analysis. Chicago: University of Chicago Press, 2001.

26 Ammerman RT, Hersen M, eds. Handbook of prevention and treatment with children and adolescents: intervention in the real world context. New York: Wiley, 1997.

27 Gorman-Smith D, Tolan P. The role of exposure to community violence and developmental problems among inner-city youth. Dev Psychopathol 1998;10:101-16.

\section{International Injury Research Specialist}

The Department of International Health of The Johns Hopkins Bloomberg School of Public Health invites applications for a full time tenure track position at the Assistant or Associate Professor level. The JHU Department of International Health is a global leader seeking to understand health problems and develop affordable means of disease reduction and health protection for underserved populations of the world. The faculty member hired will also collaborate with the JHU Center for Injury Research and Policy.

The individual will specialize in research related to injuries in developing countriesincluding the epidemiology, determinants, prevention, and economic burden of injuriesand will actively work in the design, implementation, and evaluation of public health interventions related to injuries. The individual will be expected to establish an independent research agenda through extramural funding, to teach, and to advise students in the graduate program.

\section{Qualifications}

- At least three years of research experience related to injuries, preferably related to developing countries.

- Doctoral degree in the medical social sciences or medical degree, and training or experience in epidemiology and/or public health.

Applications should include CV, cover letter, email address, and names and contact information of three references. Please email to paltman@jhsph.edu with subject heading "INJURY FACULTY SEARCH".

The Johns Hopkins University is an equal opportunity/affirmative action employer. Applications from women and minorities are encouraged. For more information email paltman@jhsph.edu. 